\title{
EVALUATION OF MECHANICAL RESISTANCE BY THE FINITE ELEMENTS METHOD OF A MACHINING TOOL WITH INTERNAL COOLING CHANNELS
}

\author{
P. H. P. França, ABSTRACT \\ and L. R. R. da Silva \\ Federal University of Uberlandia, School of \\ In this work, the strength of machining hardware for the modified turning \\ process with internal channels that circulates water as a coolant through a \\ closed system was studied. As output parameters, the mechanical strength at \\ the cutting edge and in the grooves was studied. In addition, input parameters \\ were considered different force and thermal flow conditions generated in the \\ tool's cutting edge. All analyzes performed: Influence of temperature on tool \\ stress, comparison of the maximum stresses in the tool channels with the \\ cutting edge, and the influence of coolant stress in the internal channels were \\ performed using the finite element method by the Ansys ${ }^{\circledR}$ Workbench \\ software 19.2. The main conclusions were that the parameter that most \\ influences the tension exerted on the tools is the force and that, according to \\ the force exerted, the tool will not resist the tension efforts. \\ Received: Jun 20, 2021 \\ Revised: Jun 22, 2021 \\ Accepted: Jun 30, 2021 \\ Keywords: Internal cooled tool, Finite element method, cutting forces, \\ thermal flux
}

\section{INTRODUCTION}

It is known that the temperature increase during machining is one of the main factors that compromise tool life (Machado et al., 2015). Therefore, for a more economical process, preserving the lifetime of the tools is extremely important. To control the temperature rise, there are several techniques to be adopted, and among them, one of the most common is the use of cutting fluids.

According to Debnath et al. (2014), even if these cutting fluids present advantages during machining, it is necessary to consider the environmental and social aspects, making their use doubtful. Recently, in the literature, it is common to find several studies that seek alternatives for the replacement/reduction of the application of cutting fluids, such as tool coating types, more sustainable cutting fluids, or alternative coolant techniques that may or may not involve modification of the conventional machining system.

According to (Rozzi et al., 2011), an internal cooling system for turning was presented, which consisted of cooling the cutting tool through the circulation of liquid nitrogen in microchannels inserted below the cutting tool that serves as a heat exchanger. Li et al. (2018) developed a closed-loop cooling system for cutting tools using internal coolant channels passing inside the tool shim. In addition to these internal channels, the authors relieved the shim and the negative of this relief (indentations) to increase the heat exchange area and the efficiency of this system.

Li and Shih (2007) studied the temperature distributions in a drill with internal coolant channels in the drilling of Ti-6Al-4V titanium alloy through a finite thermal model using the inverse heat transfer method. Liang et al. (2011) used a cooling system based on heat pipes to reduce the cutting temperature in dry turning of AISI 1045 steel.

In this work, a new machining technique will be presented. This technique was called ICT-Internal Cooled Tool. In short, ICT is based on cooling the machining tools internally through coolant channels. However, due to this removal of an internal mass in the inserts, its mechanical strength may be compromised, which is the focus of this work, which aims to study the strength of one of these cutting tools by varying some critical machining parameters such as force and temperature through simulations using the finite element numerical method.

The finite element numerical method has been a trendy tool in analyzing several areas of engineering, especially in machining, particularly for the study of 
phenomena that demand a large amount of cost or time. The range of uses of this method allows the analysis of various tool, material, and machine tool parameters without the need for experimental analysis.

According to Maranhão et al. (2013) the success of the finite element analysis depends a lot on the proximity of the results obtained with the experimental ones. Thus, it is essential to use rigorous input parameters to achieve a coherent result. According to Trent and Wright (2000), it was stated that the most critical parameters that influence the accuracy of numerical simulations are the material behavior curve of the part and the friction coefficient at the chip tool interface, the fracture criterion, and the thermal parameters which is one of the main focuses of this work.

\section{THE INTERNAL COOLED TOOL OPERATION}

The operation of the internal cooled tool (ICT) is based on the same principle as an air conditioning system. The cycle evaporator will cool water as a secondary fluid circulating in the tool holder and inserts with internal coolant channels. According figure 1 , in a simplified way, depicts the entire cooling system, including the insert and support.

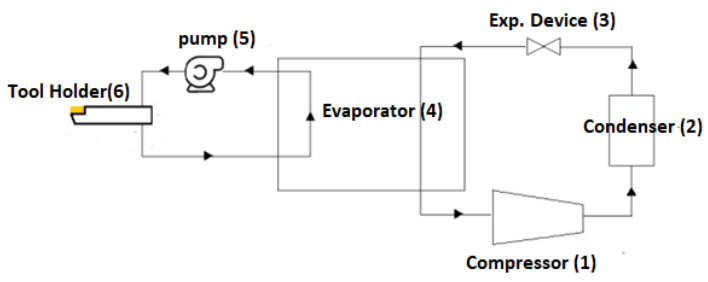

Figure 1. Diagram of the internal cooling system (ICT).

Stages (1) through (4) consist of a simple refrigeration system, similar to Chiller chillers, which generally use refrigerants such as R134a and R404a. In (1), the compressor, whose role is to compress the refrigerant fluid, increases its pressure and temperature. After passing through (1), the fluid in the vapor state will be directed to the condenser (2), where it will exchange energy with the environment, causing a decrease in its temperature and changing to the liquid state. When leaving the condenser, the fluid will go to the expansion device (3), where it will suffer a decrease in its pressure at a constant enthalpy and migrating to the evaporator (4), which will also function as a reservoir for the secondary fluid. In (4), the refrigerant will exchange heat with the secondary fluid, causing an increase in its temperature and returning to (1) in the vapor state, repeating the cycle. Still in (4), the secondary fluid, at a low temperature, will be pumped through a pump (5), where it will be delivered to (6), which is the insert and tool holder assembly. The fluid will circulate internally through channels in these two components, and after exchanging heat with both during its circulation, it will be returned to (4), where it will be cooled again, closing the second part of the cycle.

For example, figures 2 and 3 show what a tool holder and a tool modified for using ICT would look like. It is noteworthy that these figures do not represent the tool and tool holder set used in the simulations of this work.

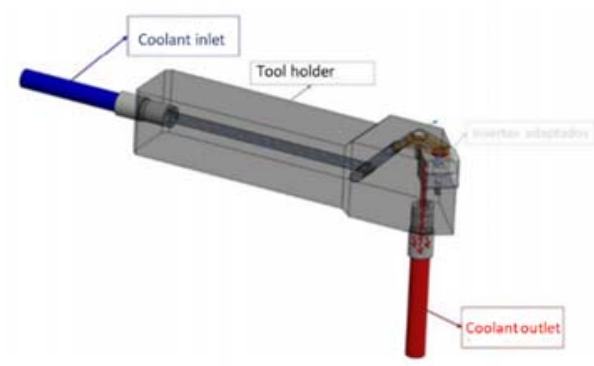

Figure 2. Path of the secondary fluid in the tool holder and tool assembly.

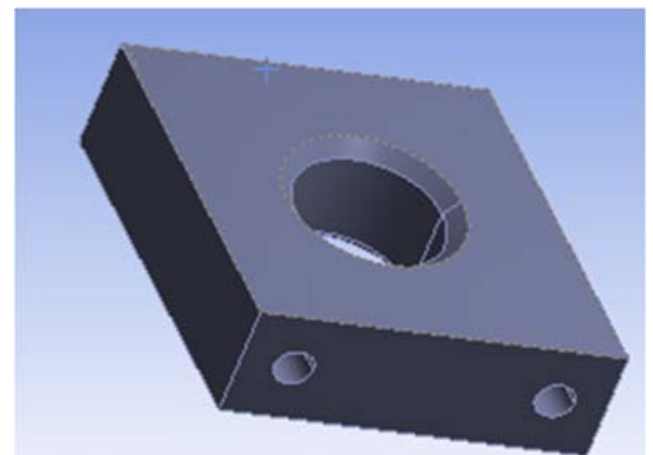

Figure 3. Modified machining insert for refrigerant circulation through simple channels.

\section{METHODOLOGY}

Figure 4 shows a representation of the simulated system. In order to simulate actual machining conditions, some of the main cutting parameters were varied, which are the compressive forces caused by the contact between the part and the tool and the thermal flow generated from the part's shear. For the heat flux and force variables, values commonly found in metal machining literature were assumed, such as Santos and Sales (2007). However, in the force parameter simulations, only the cutting force was considered. The other forces (forward and passive) were neglected. In addition, coolant and noncoolant parameters were also added to study the difference in the fluid circulation effect inside the tool. Table 1 shows the values of the parameters used. 


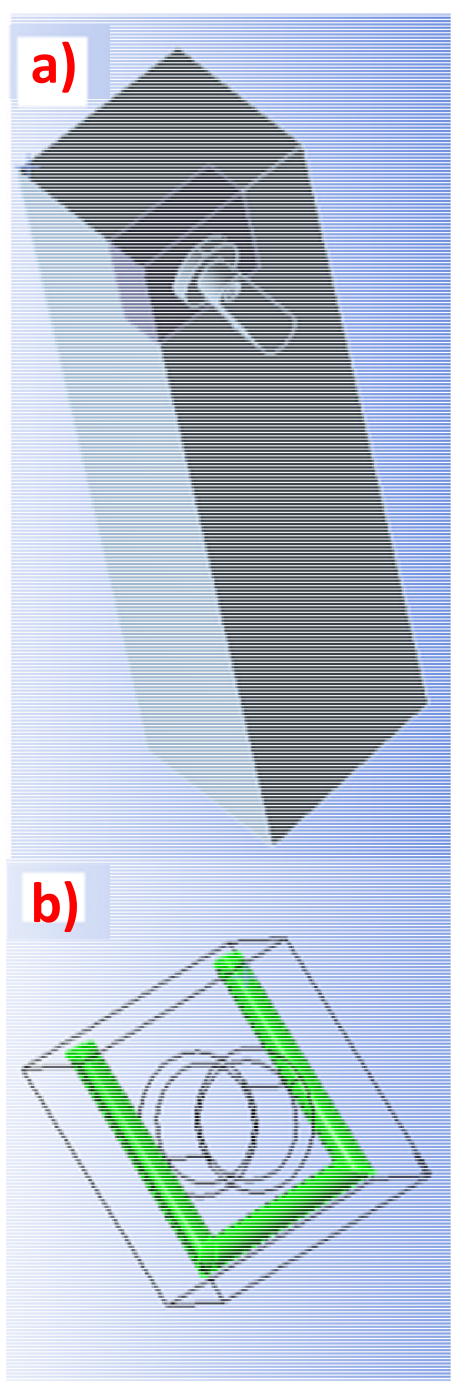

Figure 4. Cooling System used. a) tool holder and toolset; b) tool used.

Table 1 - Varied stimulation parameters during the tests.

\begin{tabular}{|l|l|l|l|}
\hline \multicolumn{4}{|c|}{ Parameters } \\
\hline Force (N) & 300 & 600 & 900 \\
\hline $\begin{array}{l}\text { Thermal } \\
\text { Flux (W) }\end{array}$ & 20 & 30 & 40 \\
\hline $\begin{array}{l}\text { Chanel } \\
\text { refrigeration }\end{array}$ & With & Without \\
\hline
\end{tabular}

Due to the complexity of parameters involved and uncontrollable variables that the model presents, it was necessary to make some assumptions to run the simulations. In which all these assumptions, described in table 2 , were based on literature values.
Table 2 - Assumptions adopted in simulation tests.

\begin{tabular}{|l|}
\hline \multicolumn{1}{|c|}{ Assumptions adopted } \\
\hline $\begin{array}{l}\text { Tool material (carbide) and tool holder }(1020 \text { steel }) \\
\text { are homogeneous }\end{array}$ \\
\hline Air convection coefficient of $20 \mathrm{~W} / \mathrm{m}^{2}{ }^{\circ} \mathrm{C}$ \\
\hline $\begin{array}{l}\text { Unidirectional force considering only the cutting } \\
\text { force }\end{array}$ \\
\hline Tool holder and tool holder emissivity 0,9 and 0,7 \\
\hline $\begin{array}{l}\text { The thermal flow of refrigerant from } 2000 \mathrm{~W} / \mathrm{m}^{2}{ }^{\circ} \\
\text { C }\end{array}$ \\
\hline
\end{tabular}

\section{RESULTS}

Before starting the tests, a mesh refinement of the system was performed to minimize the iterative errors of the simulations with a focus on the cutting edge. The refinement tests were carried out under the conditions of force (F) of $600 \mathrm{~N}$, thermal flux (ft) of $40 \mathrm{~W}$, and considering the cooling of the channels. Initially, tests were carried out with coarser meshes, and at each simulation, the stress values were filed and the execution time until reaching the permanent mesh regime.

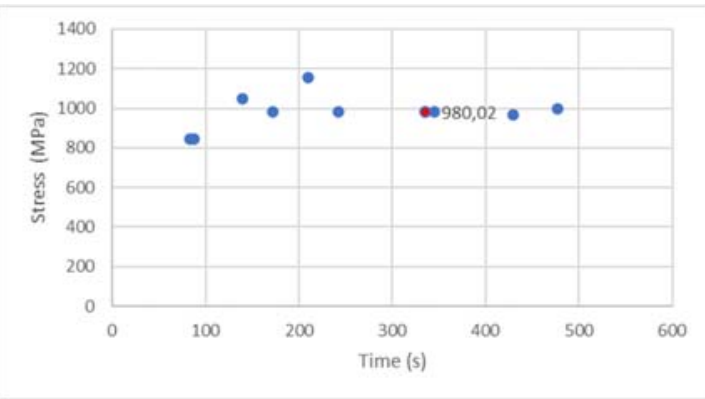

Figure 5. Refinement of the system mesh, considering the stress and time for each test.

Figure 5 demonstrates the simulations performed. It is noticed that, initially, the mesh values oscillated a lot, varying between stress of approximately $850-1200 \mathrm{MPa}$. However, when refining the mesh, it is observed that the new values tended to remain approximately constant, indicating the arrival of a permanent mesh regime. The mesh refinement was interrupted as soon as there was no significant variation between the values of the final iterations, in which the maximum discrepancy peak from the red point in Fig.4 to the last iteration was 17 $\mathrm{MPa}$. This difference can be neglected, given the average values of machining stresses that can vary from $500 \mathrm{MPa}$ to $2.5 \mathrm{GPa}$, depending on the process.

With this analysis, it was possible to see that the mesh (shown in Figure 6) that most favored the simulations would be the parameter that was marked in red, in the graph in Fig 4, due to the insignificant difference found in later values, as well as the cost computational simulations. 

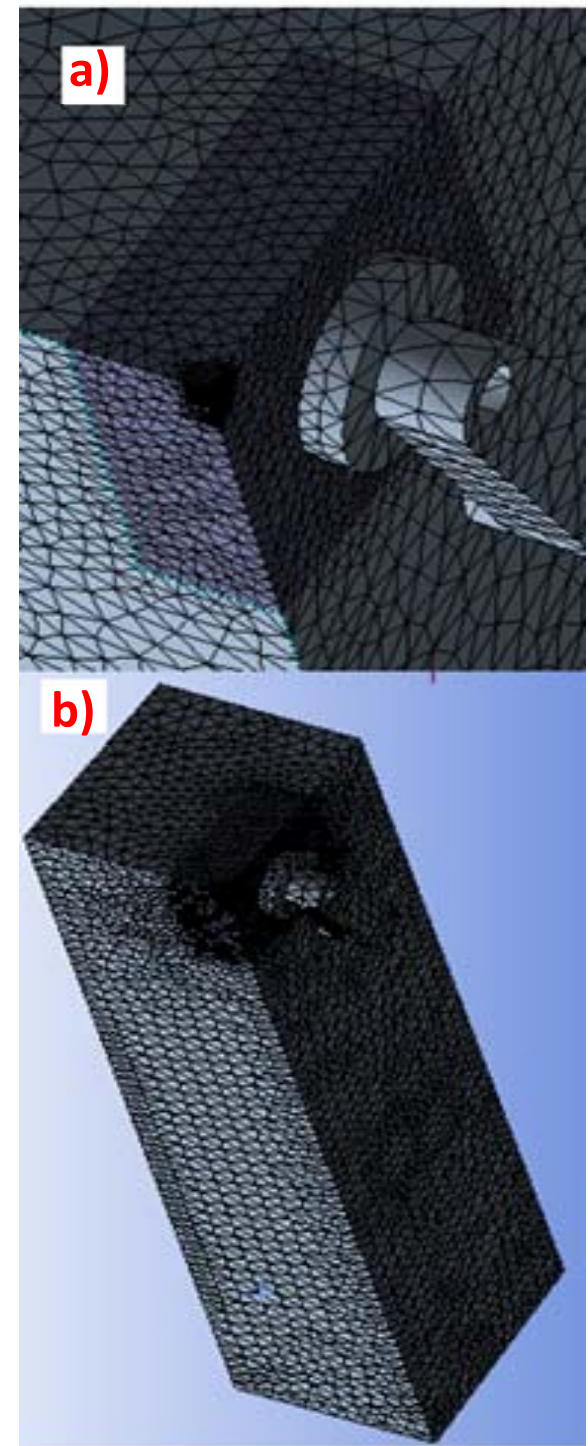

Figure 6. Mesh used to carry out the tests. (a) refinement focused on the cutting edge. (b) refinement taking into account the tool next to the tool holder.

Due to the phenomena that the temperature differential can cause, a study of the mechanical strength of the tool was carried out as a function of the variation in the thermal flux generated during metal cutting. As shown in figure 7, graphs of stress as a function of thermal flux at the cutting edge were raised, and the table indicates these stress values in $\mathrm{MPa}$. It is possible to observe that for constant force values, the $\mathrm{t}$ and tension values tended to increase proportionally with the thermal flux. The condition that presented the lowest stress values was no thermal flux on the tool's cutting edge. A justification for this temperature increase can be due to the expansion that the material undergoes. Temperature variations in materials generate thermal expansion, resulting in tractive and compressive stresses both internally and externally on the tool and in the tool holder. Another point to be taken into account is the parameter without flow (SF). Saying that there is no heat generation during machining is not consistent with reality, but considering a simulation with this condition can help understand how heat behaves.

Concerning the tension values found, it was clear that the force was the most influential factor. Increasing this variable meant much higher stress. Even though this variable showed a more significant variation between levels, it is still possible to visually state that Fig. 7 has a more significant influence when comparing with the thermal flux.

Analyzing Fig. 7, the parameters that generated higher stresses in the tool were for the simulations at a force of $900 \mathrm{~N}$. In the literature, it is possible to find the values of tensile and compression strength of a carbide tool. These can range from 6.1 to $3.2 \mathrm{GPa}$ for compression and 2.6 to $1.9 \mathrm{GPa}$ for traction. From this information, it is noted that, within the range of carbide tools, there will be cases in which some will not resist the machining efforts, specifically for cases where the force was $900 \mathrm{~N}$. It is necessary to check these strength values of the tool before carrying out any test.

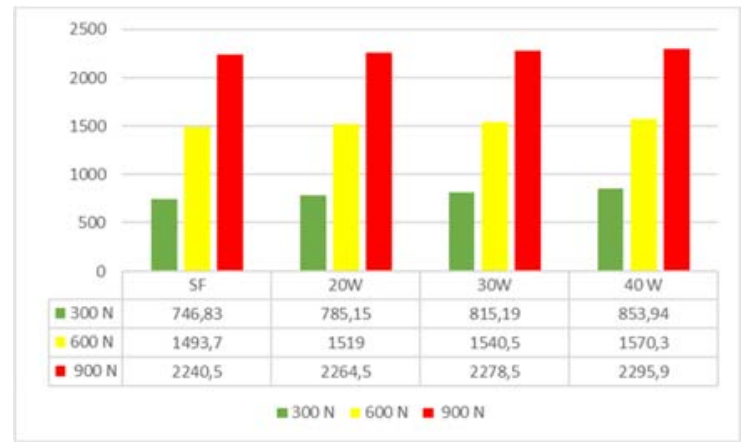

Figure 7. Influence of stress and temperature parameters in system simulations.

Before carrying out the tests, it was verified whether the internal channels would resist the stresses generated due to variations in force and thermal flux. According to figure 8 , it is possible to observe this analysis, which was carried out disregarding heat generation. When using these parameters, it was noted that the tension does not appear to be visually significant for this type of tool. The stress generated on the tool edge was, on average, about 14 times greater. Thus, it is clear that, depending on the type of internal channel used in the tools, there will be no risk of high stress generations.

Figure 9 demonstrates the stress in the internal channels obtained through the simulations. It can be seen that for the condition without thermal flux (SF), the stress of the channels presented lower values compared to the parameters that were added to the thermal flux. This can be explained by the variation in temperature difference in different regions of the tool. When heating the tool in a localized region, this 
thermal gradient around the tool causes different temperature values, generating different expansions and various tractive and compressive stresses. However, these stress variations were not significantly high. However, it may be that in some channel geometries, high stresses may arise.

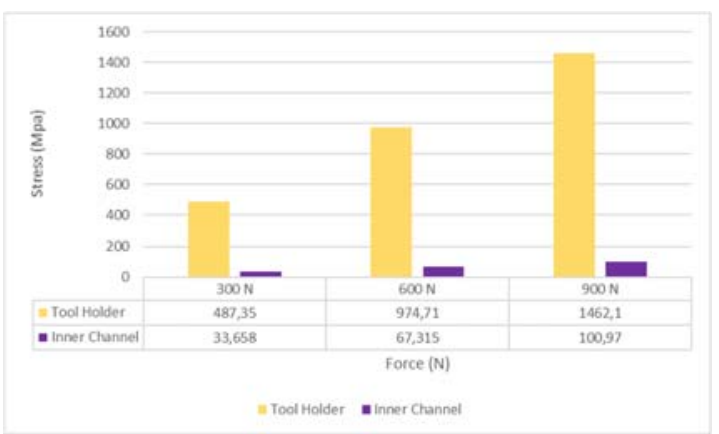

Figure 8. Maximum stresses in the tool and tool holder assembly in the condition of a tool without coolant.

Another interesting point to comment on is how the channels' stress behaved when varying the thermal flow. Conditions with lower heat flux presented higher stresses. A phenomenon that, in many engineering situations, an opposite response was expected. It could be that this occurrence was due to the propagation of the thermal flow. For the $20 \mathrm{~W}$ thermal flux, its propagation was smaller, heating up in few parts of the channels, leading to a more significant temperature variation between the tooltip and the channel, consequently causing greater expansions. As for the 30 and $40 \mathrm{~W}$ thermal fluxes, the channel underwent more significant heating, resulting in smaller temperature differentials leading to lower stress.

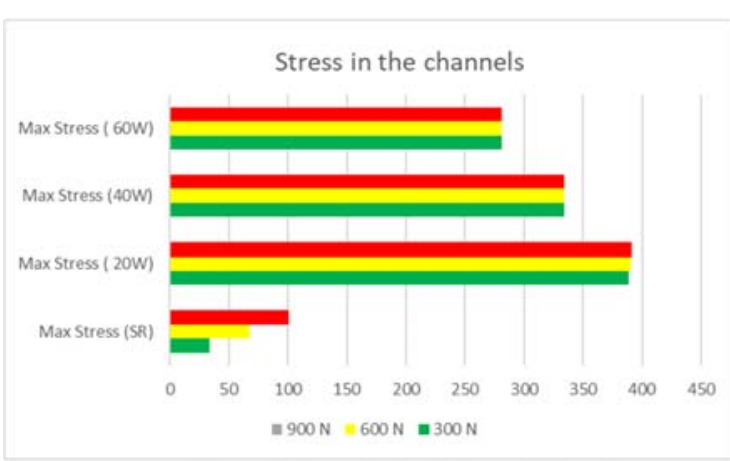

Figure 9. Stress in the tool's internal channels for different thermal flow conditions.

\section{CONCLUSIONS}

This paper presented a study about the evaluation of mechanical resistance of a internal cooled machining tool. Based on the results, the following conclusions can be drawn:
- It was found that both force and temperature variables during the machining process play a significant role in tool stresses.

- On average, the tension in the tool channels was 14 times smaller concerning the tensions generated in the tooltip.

- Using the cooled tool system, the low heat flux and other phenomena resulted in higher stress in the tool channels concerning higher heat fluxes (30 and $40 \mathrm{~W})$.

- For $900 \mathrm{~N}$ force conditions, the tools did not withstand the efforts. A suggestion for future work would be to numerically compare the simulation of a massive tool to analyze its behavior.

- The simulations showed consistent tool strength results found in the literature.

\section{ACKNOWLEDGEMENTS}

The authors are grateful to the Brazilian research agencies CNPq, FAPEMIG and Coordenação de Aperfeiçoamento de Pessoal de Nível Superior Brasil (CAPES) - Finance Code 001 for financial support.

\section{REFERENCES}

Debnath, S., Reddy, M.M., Yi, Q.S., 2014, Environmental friendly cutting fluids and cooling techniques in machining: a review, Journal of cleaner production, Vol. 83, pp. 33-47.

Li, R., Shih, A.J., 2007, Spiral point drill temperature and stress in high-throughput drilling of titanium, International Journal of Machine Tools and Manufacture, Vol. 47, pp. 2005-2017.

Li, T., Wu, T., Ding, X., Chen, H., Wang, L., 2018, Experimental study on the performance of an internal cooled turning tool with topological channel, The International, Journal of Advanced Manufacturing Technology, Vol. 98, pp. 479-485.

Liang, L., Quan, Y., Ke, Z., 2011, Investigation of tool-chip interface temperature in dry turning assisted by heat pipe cooling, The International Journal of Advanced Manufacturing Technology, Vol. 54, pp. 35-43.

Machado, Á.R., Coelho, R.T., Abrão, A.M., da Silva, M.B., 2015, Teoria da usinagem dos materiais. Editora Blucher.

Maranhão, C., Silva, L.R., Davim, J.P., 2013, Comportamento termo mecânico no microtorneamento ortogonal do aço AISI 1045 (Ck45-DIN): Simulação via elementos finitos e validação experimental, Ciência \& Tecnologia dos Materiais, Vol. 25, pp. 57-66.

Rozzi, J.C., Sanders, J.K., Chen, W., 2011, The experimental and theoretical evaluation of an indirect cooling system for machining, Journal of Heat Transfer, Vol. 133. 
Santos, S.C., Sales, W.F., 2007, Aspectos tribológicos da usinagem dos materiais, São Paulo: Artliber Editora 246.

Trent, E.M., Wright, P.K., 2000, Metal cutting. Butterworth-Heinemann. 